Provided for non-commercial research and education use. Not for reproduction, distribution or commercial use.

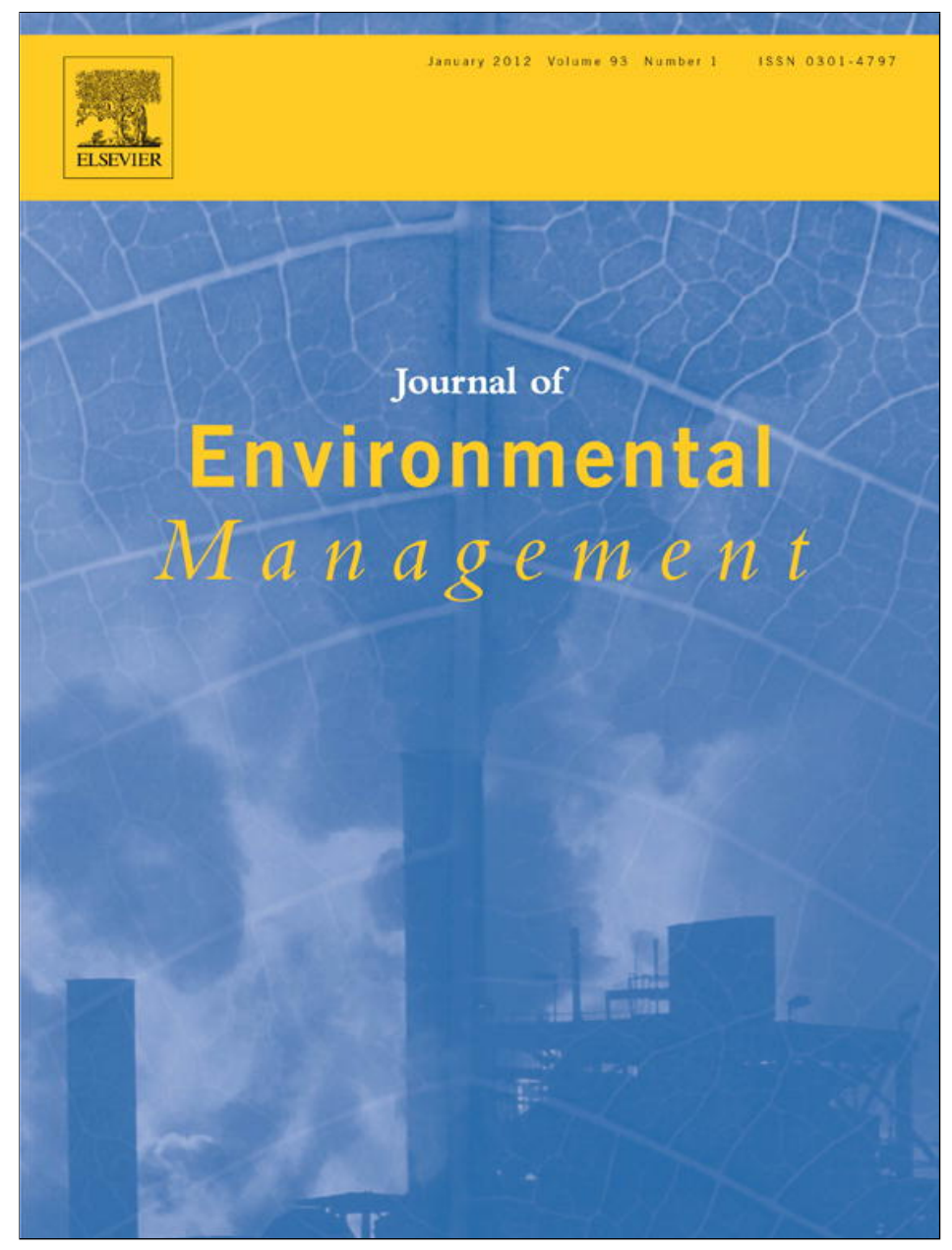

(This is a sample cover image for this issue. The actual cover is not yet available at this time.)

This article appeared in a journal published by Elsevier. The attached copy is furnished to the author for internal non-commercial research and education use, including for instruction at the authors institution and sharing with colleagues.

Other uses, including reproduction and distribution, or selling or licensing copies, or posting to personal, institutional or third party websites are prohibited.

In most cases authors are permitted to post their version of the article (e.g. in Word or Tex form) to their personal website or institutional repository. Authors requiring further information regarding Elsevier's archiving and manuscript policies are encouraged to visit:

http://www.elsevier.com/copyright 


\title{
Atomized sludges via spray-drying at low temperatures: An alternative to conventional wastewater treatment plants
}

\author{
Joan A. Cusidóa ${ }^{a}$, Lázaro V. Cremades ${ }^{\mathrm{b}, *}$ \\ a Departament de Física i Enginyeria Nuclear, Universitat Politècnica de Catalunya, Pere Serra 1-15, 08190 Sant Cugat del Vallès, Barcelona, Spain \\ ${ }^{\mathrm{b}}$ Departament de Projectes d'Enginyeria, Universitat Politècnica de Catalunya, ETSEIB, Avda. Diagonal 645, 08028 Barcelona, Spain
}

\section{A R T I C L E I N F O}

\section{Article history:}

Received 26 November 2010

Received in revised form

6 March 2012

Accepted 25 March 2012

Available online $\mathrm{xxx}$

\section{Keywords:}

Spray-drying

Sludge

Atomizer

Wastewater treatment plant

\begin{abstract}
A B S T R A C T
Removal of sludges from Wastewater Treatment Plants (WWTP) represents a serious worldwide environmental problem for which alternatives other than their simple incineration are investigated. In this work the treatment of raw sludge from urban WWTP by means of a minimization process through spraydrying is analyzed as well as some proposals for revaluating the resulting dry product. Analysis is supported by some experimental results obtained with a laboratory spray dryer. The experimental procedure at laboratory scale is extrapolated to an industrial plant scale. An economic analysis of the proposal in relation to other possible sludge treatments is presented, taking into account in this case the comparison between the costs of the processes of sludge thickening, stabilization and dehydratation and the costs of spray-drying (especially power consumption), minimization of the final waste and reuse options. Finally, an environmental balance of the process is presented. In contrast with the classical treatment line, this alternative allows transforming sludges, i.e., a waste, into a valuable product with several applications.
\end{abstract}

(c) 2012 Elsevier Ltd. All rights reserved.

\section{Introduction}

The main problem in treating urban wastewaters is basically reduced to finding an environmentally correct technology at the lowest cost. So far, the typical technology adopted world-wide in wastewater treatment plants (WWTP) consists of the following sequential stages (Nebel and Wright, 1999): 1) preliminary treatment (removal of solid wastes); 2) primary treatment (separation of organic matter particles); 3 ) secondary treatment (removal of dissolved and colloidal organic matter), and 4) tertiary treatment (optional) (cleaning and final disinfection). It is really a complex and costly process requiring a large surface layout and qualified staff for operation and maintenance.

Wastewater sludges are very complex colloidal systems with a varying content of living and dead biomass, exopolymers, inorganic particles and water (Sobisch and Lerche, 2000). More specifically, raw sludge forms a black and smelly liquid that is 95-98\% water and which may contain pathogen microorganisms. For this reason sludges are considered as biological hazard wastes. Not long ago, it was thought that raw sludge was a valueless material that should be discarded, and then it was

\footnotetext{
* Corresponding author. Tel.: +34934011750.

E-mail address: lazaro.cremades@upc.edu (L.V. Cremades).
}

incinerated, disposed of in landfills and/or thrown into the ocean. But the huge amounts of sludges produced (about $1 \mathrm{~kg}$ per inhabitant every day) make all these options environmentally unacceptable.

Production of dried sludge (by thermal or rotary drying) that can subsequently be used for agricultural purposes or as a fuel seems to be the best long-term option (Christoulas et al., 2000). However, in any case the economical value and/or usefulness of the dried sludge for these applications does not usually compensate for treatment, transportation and environmental costs (Spinosa et al., 2011).

In this paper an alternative to treat raw sludges from WWTP is presented. This alternative is based on spray-drying the sludges. To evaluate the process, some experiments have been carried out with a laboratory-scale spray dryer. In contrast to the classical treatment line, this alternative allows transformation of the sludge, i.e., a waste, into a valuable product with several applications.

The idea of applying the technology of spray-drying to sludges is not unknown. Spray-drying of thickened digested sludge (12-15\% solids) has been successful in the U.S. since 1938 (Komline, 1947). There are also several patents that claim the intellectual rights to that invention; for example, Schneider (1996) patented a system for reducing moisture content of sludge-like materials. Finally, a detailed review (Chen et al., 2002) also refers to the possibility of using this technology as a method of direct drying, emphasizing 
that there was no such facility in the U.S. at that moment. However, we do know that there is a plant which has implemented this proposed technology for treating the sludges from potable water treatment at Barcelona (Spain) to demonstrate its feasibility (Cusidó, 2001). Thus, sludge drying in general (flocculation, electroosmotic dewatering and then thermal drying, etc.), and spraydrying of sludges in particular, are issues still under investigation, as evidenced by several recent works (Amos, 1998; Novak, 2006; Arlabosse and Chitu, 2007; Woo et al., 2007).

\section{Experimental}

The new process proposed is based on spray drying raw sludges (90-95\% water) coming from the classical primary treatment in WWTP. As previous preliminary step, these raw sludges have to be filtered through wire mesh to separate particles that could obstruct the inlet hole of the spray-dryer wheel. In contrast with the classical treatment of raw sludge, there is no need for sludge floculation. But, gases exiting the spray dryer-basically steam, with traces of volatile organic compounds (VOC) and some particles of sludges (see afterwards)-have to be cleaned before they are released.

The main equipment of this process is the spray dryer. Some experiments have been carried out at laboratory scale by using the spray dryer NIRO Mobile Minor. Relevant data about the raw sludges tested in this work are listed in Table 1. The laboratory-scale procedure followed is described next.

\subsection{Preparation of slurry}

WWTP raw sludge tested contained $94 \%$ water. The solid part consisted of inorganic and organic particles, and molecules in colloidal suspension. For the formation of raw sludge, coagulants such as trivalent iron salts and polyelectrolytes flocculants were added. First, the slurry must have a basic $\mathrm{pH}(\approx 8)$ and, if necessary, its rheology must be corrected by adding some deflocculants (sodium polyphosphate), which had not been necessary in this work, in order to reach a viscosity of around 300-400 cP. Finally, the slurry was sieved through a $1.25 \mathrm{~mm}$ mesh. Heating the slurry slightly improves the performance of the operation.

\subsection{Spray drying}

The spray-drying process involves the removal of the liquid phase of a slurry on one continuous operation to get the solid phase as dry as possible. The slurry tested contained $94 \%$ of liquid phase. The spray drier worked under the following conditions: hot air inlet temperature: $350^{\circ} \mathrm{C}$; centrifugation speed: $30,000 \mathrm{rpm}$; inlet flow of slurry: $68 \mathrm{~cm}^{3} / \mathrm{min}$; inlet temperature of slurry: $90^{\circ} \mathrm{C}$; outlet temperature of dry sludge: $120^{\circ} \mathrm{C}$.

Inlet and outlet temperatures were chosen especially low given the high content of organic matter that could be decomposed and produce dangerous atmospheres inside the spray drier. A scheme of

Table 1

Main characteristics of raw sludges from WWTP (physico-chemical treatments) used in this study.

\begin{tabular}{ll}
\hline Origin & WWTP from Sabadell (Spain) \\
Color & Black \\
Odor & Yes \\
Lower heating value & $14,080 \mathrm{~kJ} / \mathrm{kg}$ \\
$\mathrm{COD}$ (dry basis) & $219,866 \mathrm{mg} \mathrm{O} / \mathrm{kg}$ \\
$\mathrm{BOD}_{5}$ (dry basis) & $38,104 \mathrm{mg} \mathrm{O} / \mathrm{kg}$ \\
$\mathrm{pH}$ & 8.3 \\
Moisture & $94 \%$ \\
Clay content (dry basis) & $6.5 \%$ \\
Inorganic matter (dry basis) & $25.3 \%$ \\
\hline
\end{tabular}
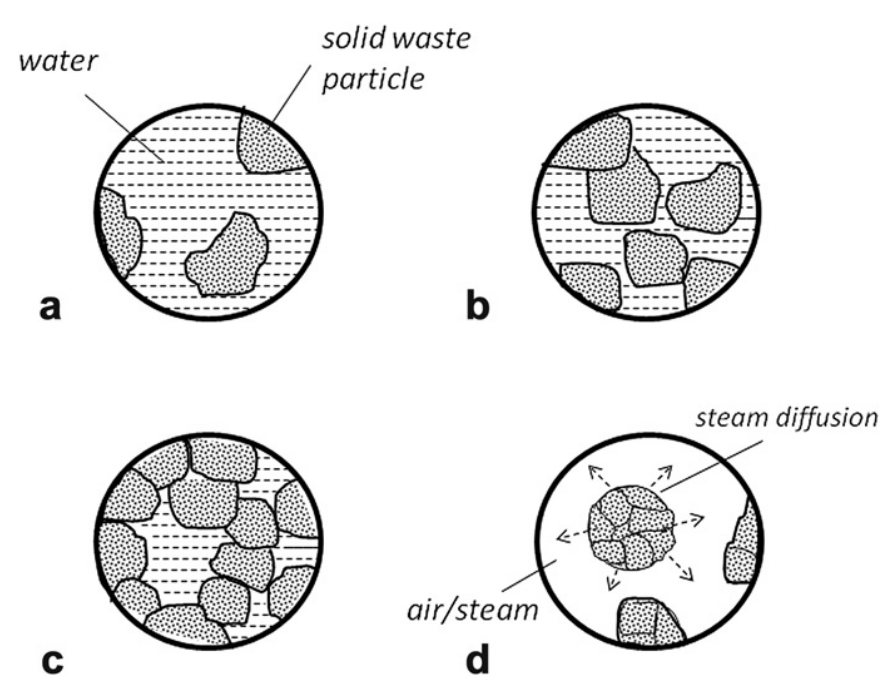

Fig. 1. Schematic view of different drying stages of raw sludge for the proposed treatment: a) raw sludge with $80 \%$ water content; b) raw sludge after centrifugation, $>50 \%$ water; c) aggregates of particles with interstitial water after spray-drying; d) final dried spherical atomized sludge, $<5 \%$ water.

the estimated spray-drying process is shown in Fig. 1, related to the formation of atomized particles.

\subsection{Resulting product}

The product has low density $\left(270 \mathrm{~kg} / \mathrm{m}^{3}\right)$. Size analysis was done by using a conventional mechanical sizer Filtra 76-13. Sizes of detected particles ranged from 100 to $400 \mu \mathrm{m}$ (Fig. 2). A summary of the main characteristics of the product is presented in Table 2. Volatile suspended solids (VSS) emitted during the spray-drying process are estimated as $11.6 \%$, which is equal to the difference between organic matter content in raw sludge (74.7\%) and in atomized sludge (62.9\%).

Although it is noted that the sprayed sludge does not smell, it should be mentioned that, because of its granulometry, atmospheres formed from the product in contact with moisture from the pituitary can result in a pungent odor of hydrogen sulfide. The final product is stabilized and seems to be pathogen-free because no change in color, texture, moisture, and/or leachates with time has been observed in 6-year-old samples.

Finally, its chemical composition corresponds to the presence of aluminium, calcium, and phosphorus, as well as non-halogenated solvents. X-ray diffraction (Fig. 3) indicates the presence of mineral species such as $\alpha$-quartz, calcite and dolomite mostly,

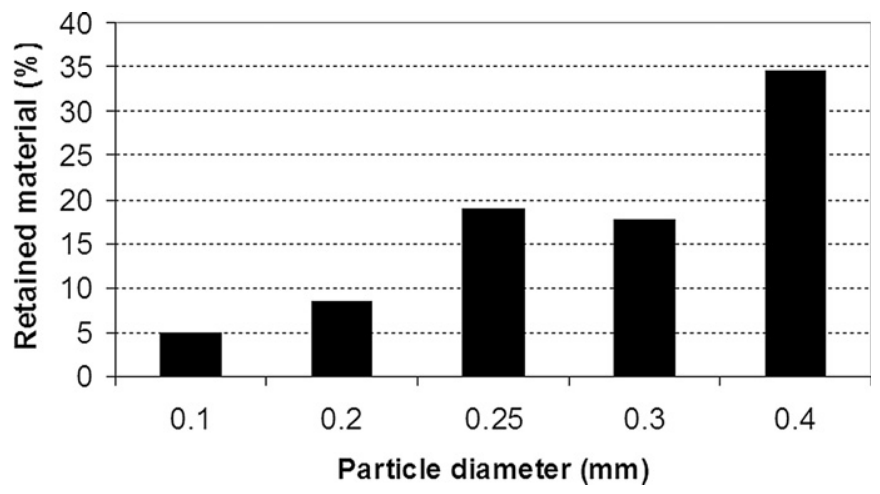

Fig. 2. Size analysis of the atomized sludges obtained. In case of full scale, the diameter of particles is slightly larger. 
Table 2

Main characteristics of spray-dried sludge from WWTP (physico-chemical treatments) obtained.

\begin{tabular}{ll}
\hline Origin & WWTP from Sabadell (Spain) \\
Color & Dark grey (concrete) \\
Odor & No \\
Density & $270 \mathrm{~kg} / \mathrm{m}^{3}$ \\
Weight loss at $500{ }^{\circ} \mathrm{C}$ & $62.9 \%$ \\
Moisture & $5.0 \%$ \\
\hline
\end{tabular}

although more than $60 \%$ is organic matter (amorphous phase), is similar in composition to the conventional secondary wet sludge.

\section{An alternative plant proposed}

Once the feasibility of spraying WWTP raw sludge has been verified experimentally, the possibility of building a plant capable of full-scale operation is proposed. This plant would operate as follows.

- Step 1: Primary treatment based on conventional screening, sand removal, and degreasing. Its aim is to equalize the sludge prior to a phase of sedimentation.

- Step 2: High-speed centrifugation of raw sludges. Clarified water is sent to a tertiary treatment for reuse. The resulting sludge would be sieved and prepared as sprayable slurry.

- Step 3: Spray-drying of sludges. Vapors would be biofiltered to eliminate odors and to condense them for further tertiary treatment and reuse. The solid fraction from the atomizer and cyclone would be collected into appropriate hoppers to prevent dust from escaping into the atmosphere. Finest particles would be removed by an electrostatic filter at exhaust gases.

- Step 4: Adequate packaging of the solid fraction as a product for shipment or destination. It should take care of minimizing air handling in order to prevent fire/explosion hazard. The resulting water would be discharged into the river basin or reused once the residual pollutants are removed (if any, in a tertiary treatment plant).

A plant of this kind would not need any secondary treatment and would reduce by over $50 \%$ the area of land occupied. A scheme of the proposed sludge treatment plant is shown in Fig. 4.

\section{Environmental considerations}

The procedure proposed for the spray-drying process would require an environmental analysis of both the spray drying operation, and the product obtained. In this section we analyze only the first one of these stages.

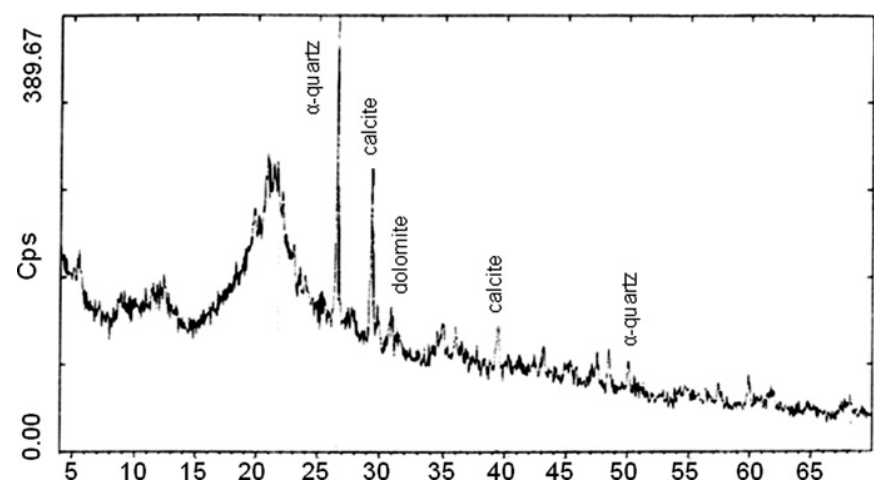

Fig. 3. X-ray diffractometry of the atomized sludges. An organic amorphous phase and inorganic $\alpha$-quartz, calcite and dolomite are detected as majority components.

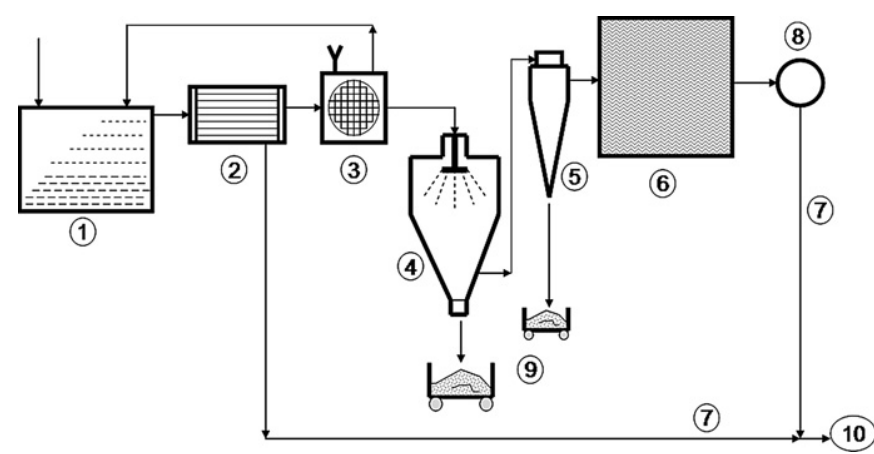

Fig. 4. Schematic view of different steps for the proposed plant treatment based on spray drying sewage primary or colloidal sludges: 1) settler, 2) high velocity centrifugation, 3) sieve and additives, if any, 4) spray drier, 5) cyclone, 6) gas cleaning (biofilter), 7) clear water, 8) condenser, 9) dried sludge, and 10) tertiary treatment, if necessary.

First, in relation to the reception of WWTP primary or colloidal sludges and their storage, environmental impact is negligible, since they consist of a liquid waste that can be easily transported through ducts and stored in ponds like those that are used in the treatment lines of conventional sludges. Also, the processes of sieving sludges do not require preventive measures beyond those in a conventional WWTP, being an automated process that does not require manipulation. Removal of such wastes gives off intense smells that are easily treatable through suitable ventilation systems and recommended use of masks and hermetic glasses.

The outlet stream from the spray drier goes into a cyclone system to recover the fraction of settled particles which otherwise could leave to the atmosphere with acceptable efficiency. Outlet gases include $\mathrm{CO}_{2}$ and $\mathrm{NH}_{3}$, mostly, but also some $n$-heptane, $\mathrm{CH}_{4}$, and volatile fatty acids, as well as other trace gases.

Spray drying is done at low temperature $\left(<120^{\circ} \mathrm{C}\right)$. Because of the relatively low temperature, organic compound gases that are evacuated along with hot air and water vapor through the chimney come off on a low odor level in the surroundings of the WWTP. Probably, a post-combustion of gases or a biofilter would totally remove the remains of VOC. In any case, although this stage is not considered as essential in the proposed process, it could be easily adopted given its low cost of implementation.

Concerning the storage and transportation of the final product, it is important to remark that this product is dry and dusty, with small granulometry $(0.1-0.4 \mathrm{~mm})$. Left to stand, it does not release any odor, but when breeze stirs up dust and it enters the nostrils, in contact with the pituitary (which is moist), an extremely unpleasant odor results. Therefore, hermetic systems of packing or closed tanks for its storage are required.

Concentrations of methane, hydrocarbons and other volatile organic compounds must be monitored and controlled through safety detectors throughout the entire treatment plant because a localized deflagration can spread to the rest of the plant. The internal atmosphere of the spray chamber should receive a special attention. In this work, in order to prevent this problem, tests were carried out, starting with a very dilute slurry and then increasing the concentration of the slurry up to the working concentration (82\% moisture).

Other considerations relevant to human manipulation call for the use of masks as well as natural and/or forced controlled ventilation of storage hoppers. Oxygen concentration in the entire building should be controlled as proposed in the operational circular applied in the UK (HSEOC, 2005).

There are no specific regulations for emissions from spraydrying processes; however, gaseous and particulate matter 
emissions in general should not exceed their legal limit values, being below $50-75 \mathrm{mg} / \mathrm{Nm}^{3}$, depending on the pollutant (Enrique et al., 2000). Otherwise, these levels are easy to achieve by cleaning organic vapors emitted from the cyclone outlet.

\section{Applications of spray-dried sludges as raw material}

There are some conventional methods for final disposal of sewage sludge, which can be grouped into three groups (Werther and Ogada, 1999): a) incinerated sludges: application of the ash in concrete; b) co-combustion: application in cement, ceramics and asphalt, and c) alternatives to the above: wet oxidation, pyrolysis and gasification.

The proposed raw sludge drying process by spray-drying would allow applying the product to cement, ceramics, asphalt and other possibilities. Among possible applications of the spray-dried product, we can mention the following ones:

- Additive in the production of cement. Because of their high carbonate content, as well as other inorganic compounds, spray-dried sludges could prove to be a good additive to be incorporated in the final process of the industrial cement production.

- Raw material for structural ceramics. Their inorganic contents of argillaceous origin as well as the carbonated wastes could allow to be added in ceramic matrices for different products: bricks, tiles, special ceramic pieces, etc. And this can be easily done whenever the addition of spray-dried sludges in the raw materials does not exceed $10-15 \%$ in weight. In excess from these percentages some problems of annoying but non-toxic gaseous emissions could arise. When $10 \%$ atomized sludges were incorporated into clays during ceramic firing, we have measured the following main VOC in normal conditions by gas chromatography: benzaldehyde $\left(757 \mu \mathrm{g} / \mathrm{m}^{3}\right), \quad$ isocianebenzene + benzonitrile $\left(607 \mu \mathrm{g} / \mathrm{m}^{3}\right)$, benzene $\left(478 \mu \mathrm{g} / \mathrm{m}^{3}\right)$, toluene $\left(324 \mu \mathrm{g} / \mathrm{m}^{3}\right)$, isocianemethane $\left(1557 \mu \mathrm{g} / \mathrm{m}^{3}\right)$, and benzofuran $\left(99 \mu \mathrm{g} / \mathrm{m}^{3}\right)$. All these values are below their TLV from ACIGH.

- Additive in organic fertilizers (up to 5-10\%). Probably this application for spray-dried sludges has the greatest added value, although it has not yet been properly studied at a scientific level.

As with conventional WWTP sludge, it can be also used for recovering soils with the advantage of its easier transportation and management. For soil remediation, farming and composting, application of sprayed sludge has clear advantages since there is no pathogen pollutant load (sterilized product), which is one of the major handicaps in its actual implementation (Wlart and Schwartzbrord, 1997).

The application in the production of cement or addition in concretes and mortars has been promoted and studied in different countries with acceptable results (Valls and Vázquez, 2002). The use of atomized dry sludge might have better possibilities for these applications. There is also less health risk due to handling.

Likewise, the use as raw material in the production of ceramics has also been proposed for conventional treatment sludges (Cusidó et al., 2003; Otero et al., 2003). Sprayed sludge can be incorporated into the ceramic matrix in higher percentages with advantages in handling, as in the previous case.

Finally, the sprayed sludge enables new applications, such as the manufacture of ceramic coatings (ornamental tiles, floor tiles, etc.). It can also be applied as fly ashes in the formulation of mortars and concretes. Composition and rheological properties of sprayed sludge suggest its use as oxidizer in the form of briquettes, alone or combined with other substances in incinerators or cement plants.
Obviously, without the presence of moisture, it can be stored in insulated and compact packages because the material is stable (neither fermentation nor gas emission), which is a remarkable advantage.

\section{Approximation to an economical assessment}

It is evident that the treatment of raw sludges by means of the proposed process is more expensive than the conventional settling screening, homogenization, thickening, and dehydration treatments. Nevertheless, when adding the costs of removal of resulting sludges by different routes (practically reduced to incineration or land disposal), the cost balance makes the spray-drying technique economically interesting.

Raw sludge usually contains more than $98 \%$ water, which can be reduced by centrifugation to $85-90 \%$. The energy balance on a particle in the drying process is (Green, 2008):

$Q=Q_{\text {ext }}+Q_{\text {drop }}+Q_{\text {react }}$

where $Q=$ total rate of heat transfer; $Q_{\text {ext }}=$ rate of heat transfer from an external heat source; $Q_{d r o p}=$ vaporization heat rate; $Q_{\text {react }}=$ rate of heat transfer caused by chemical reactions. The term Qreact is zero in this work because spray-drying at low temperature does not cause any chemical reaction to consider. Then, energy balance can be rewritten as follows:

$Q=h A\left(T_{\text {gas }}-T_{\text {drop }}\right)+\lambda_{\mathrm{v}} \frac{\mathrm{d} m_{\mathrm{drop}}}{\mathrm{d} t}=m_{\mathrm{drop}} C p_{\mathrm{drop}} \frac{\mathrm{d} T_{\mathrm{drop}}}{\mathrm{d} t}$

where $h=$ convective heat transfer coefficient; $A=$ heat transfer area; $T_{\text {gas }}=$ temperature of heating gas; $T_{\text {drop }}=$ initial temperature of droplets; $\lambda_{v}=$ latent heat of vaporization per mass unit; $m_{\text {drop }}=$ mass of droplets; $C p_{\text {drop }}=$ specific heat of droplets; $t=$ time. The first term in Eq. (2) represents the heat transfer by convection. The second term represents the latent heat of vaporization of droplets. Therefore, the energy contribution is invested in basically water evaporation. Certainly, from an economic point of view, it involves a high cost which can be estimated as $0.336 € / \mathrm{kg}$ of dry sludge, while purified water production (after condensation) can cost as much as $3.36 € / \mathrm{m}^{3}$ (Fuentes, 2007).

Let us assume that the cost of the spray-dried sludge production (5\% moisture) is $0.33 € / \mathrm{kg}$ and the cost of the humid sludge $(60 \%$ moisture) from the conventional treatment is $0.10 € / \mathrm{kg}$. However, for each $1 \mathrm{~kg}$ of spray-dried sludge, $2.375 \mathrm{~kg}$ of humid sludge would be produced from the conventional treatment $(=95 \mathrm{~kg}$ dry matter in spray-dried sludge $/ 40 \mathrm{~kg}$ dry matter in humid sludge). Therefore, for an equal amount of dry matter, the comparative cost will be in the last case $0.24 € / \mathrm{kg}$, which means a difference of only $0.09 € / \mathrm{kg}$. Detailed economic analysis of thermal drying technologies can be found in Mujumdar and Zhonghua (2007).

There are a number of alternatives for sludge disposal from conventional WWTP, from direct incineration (Khiari et al., 2007) and thermal drying (Pankratz, 2005) up to spray drying, which has already been reported by many authors since 1939 . As said above, spray drying has also been the object of patents (Schneider, 1996) and there are yet few practical achievements (TTPL, 2010). But, for atomized sludges, the alternatives are the same with better performance.

It should be noted that spray-drying allows the use of cogeneration systems which would reduce energy costs considerably. Besides, there is a saving in the cost of implementation of secondary treatment and its corresponding line for sludge treatment in a WWTP. Then, economical differences in the global cycle of each of the systems are reduced drastically, making the alternative system feasible. This alternative provides, moreover, the 
following advantages: a) reduction of area occupied by the plant; b) integrated and simplified system; c) line of purified, sterile and better quality water; d) reduction of $60 \%$ or more of the final solid waste; e) more opportunities for adding value from solid waste, and f) reduced sanitary risks.

\section{Conclusions}

Disposal of sewage sludge in landfills is prohibited in the EU if they contain more than 60\% organic matter (EU, 2006), which makes the proposal here presented interesting because of the reduced volume and increased possibilities of reuse.

The proposal of thermal drying by atomization is an alternative to the conventional lines of treatment of WWTP sludges at laboratory scale. Through a simple preparation of raw sludges and without adding deflocculants or dispersing products, dry sludges are obtained which reduce their volume dramatically. Additionally, these dry sludges could also be easily used in many economic sectors (cement products, ceramics for construction, soil corrections, etc). The process has a very favorable economic balance in comparison to other treatments and removal procedures. With respect to the conventional treatments, the spray-drying process shows a better outcome because of the results with actual technology, its reliability, and its environmental advantages. All of the above evidence makes this proposal plausible today.

\section{References}

Amos, W.A., 1998. Report on Biomass Drying Technology. National Renewable Energy Laboratory, NREL/TP-570-25885, Golden, Colorado.

Arlabosse, P., Chitu, T. 2007. Identification of the limiting mechanism in contact drying of agitated sewage drying. Drying Technol. 25 (4), 557-567.

Chen, G., Yue, P.L., Mujumdar, A.S., 2002. Sludge dewatering and drying. Drying Technol. 20 (4-5), 883-916.

Christoulas, D.G., Andreadakis, A.D., Kouzeli-Katsiri, A., Aftias, E., Mamais, D., 2000. Alternative schemes for the management of the sludge produced at Psyttalia. Water Sci. Technol. 42 (9), 29-36.

Cusidó, J.A., 2001. Procedimiento de obtención de un producto pulverulento a partir de la fracción de rechazo de una planta potabilizadora de agua, producto obtenido con tal procedimiento y utilización de tal producto. Patent no. 009802661, Publication no. 2157752, Spain (in Spanish).
Cusidó, J.A., Cremades, L.V., González, M., 2003. Gaseous emissions from ceramics manufactured with urban sewage sludges during firing processes. Waste Manage. 23 (3), 273-280.

Enrique, J.E., Monfort, E., Busani, G., Mallol, G., 2000. Reciclado de aguas residuales en la fabricación de baldosas cerámicas. Boletin Soc. Esp. Ceram. Vidrio. 39 (1), 149-154 (in Spanish).

EU, 2006. Directive 2006/12/EC of the European Parliament and of the Council of 5 April 2007 on Waste. URL: http://eur-lex.europa.eu/LexUriServ/LexUriServ.do? uri=OJ:L:2006:114:0009:0009:EN:PDF (accessed 10.02.10)

Fuentes, S., 2007. La gestió de fangs de les estacions depuradores d'aigües residuals. Diputació de Barcelona (in Catalan).

Green, D.W. (Ed.), 2008. Perry's Chemical Engineers' Handbook, eighth ed. McGrawHill, New York.

HSEOC, 2005. Sewage Sludge Drying Plant. Health and Safety Executive Operational Circular 847/9, UK.

Khiari, B., Marias, F., Vaxelaire, J., Zagruba, F., 2007. Incineration of a small particle of wet sewage sludge: a numerical comparison between two states of the surrounding atmosphere. J. Hazardous Mater. 147, 871-882.

Komline, T.R., 1947. Experiences in thickening and drying of sludge. Sewage Works J. 19 (5), 806-810.

Mujumdar, A.S., Zhonghua, W., 2007. Thermal drying technologies - cost-effective innovation aided by mathematical modeling approach. Drying Technol. 26 (1), 145-153.

Nebel, B.J., Wright, R.T., 1999. Ciencias ambientales. Ecología y desarrollo sostenible, sixth ed. Pearson Educación, Mexico (in Spanish).

Novak, J.T., 2006. Dewatering of sewage sludge. Drying Technol. 24 (10), 1257-1262.

Otero, M. Rozada, F. Calvo, L.F. García, A.I. Moran, A. 2003. Kinetic and equilibrium modelling of the methylene blue renoval from solution by adsorvent materials produced from sewage sludges. Ambiental Eng. J. 15 (1), 59-68.

Pankratz, T.M., 2005. Advances in desalination technology. Int. J. Nucl. Desalination 1 (4), 451-455

Schneider, H., 1996. Arrangement for reducing the moisture content of sludge. U.S. Patent 5480539.

Sobisch, T., Lerche, D., 2000. Investigations on sludge dewatering with the separation analyser LUMiFuge 114. CPS: envechem/0010001.

Spinosa, L., Ayol, A., Baudez, J.C., Canziani, R., Jenicek, P., Leonard, A., Rulkens, W., $\mathrm{Xu}, \mathrm{G}$., Van Dijk, L., 2011. Sustainable and innovative solutions for sewage sludge management. Water 3 (2), 702-717.

TTPL, 2010. Transparent Technologies Private Limited. India. URL: http://www.ttpl. co.in (accessed 10.02.10).

Valls, S., Vázquez, E., 2002. Leaching properties of stabilized/solidified cementadmixtures-sewage sludges systems. Waste Manage. 22 (1), 37-45.

Wlart, J., Schwartzbrord, J., 1997. Parasitological contamination of urban sludge used for agricultural purposes. Waste Manage. Res. 15 (4), 429-436.

Werther, J., Ogada, T., 1999. Sewage sludge combustion. Progr. Energy Combust. Sci. 25, 55-116.

Woo, M.W., Daud, W.R.W., Tasirin, S.M., Talib, M.Z.M., 2007. Optimization of the spray drying operating parameters - a quick trial-and-error method. Drying Technol. 25 (10), 1741-1747. 